\title{
FATORES CONDICIONANTES DA FORMAÇÃO DO MEIO TÉCNICO- CIENTÍFICO-INFORMACIONAL NA REGIÃO METROPOLITANA DO VALE DO PARAÍBA E LITORAL NORTE
}

\author{
CONDITIONING FACTORS FOR FORMATION OF SCIENTIFIC- \\ TECHNICAL-INFORMATIONAL ENVIRONMENT OF THE \\ METROPOLITAN REGION OF THE VALE DO PARAÍBA AND LITORAL \\ NORTE
}

\author{
Daniel José de Andrade ${ }^{1}$ \\ Adriane Aparecida Moreira de Souza ${ }^{2}$
}

\section{RESUMO}

O atual período tecnológico tem origem após 1970 e caracteriza-se, segundo Santos (2012), pela forte interação da técnica, ciência e informação, elementos responsáveis pelo surgimento de uma nova estrutura social e econômica, com implicações diretas no espaço geográfico, agora denominado meio técnico-científico-informacional. No Brasil, a distribuição de infraestrutura técnica para a modernização do país revela a heterogeneidade no território derivada das estratégias adotadas pelo Estado e pelo capital industrial e financeiro. Nesse contexto de desigualdades socioespaciais se insere a recém-criada Região Metropolitana do Vale do Paraíba e Litoral Norte (RMVPLN), composta por municípios cujas características são mais ou menos representativas do atual período tecnológico. Nesse sentido, este trabalho dedica-se a analisar o processo de modernização da RMVPLN, considerando as políticas públicas voltadas ao desenvolvimento econômico e tecnológico, implementadas ao longo das últimas cinco décadas e seus reflexos na região.

Palavras-chave: Modernização econômica. Meio técnico-científico-informacional. Políticas públicas.

\begin{abstract}
The current technological period was initiated in the 1970s and is characterized, according to Santos (2012), by a strong interrelation between technology, science and information, elements which are produced a new social and economic structure with direct implications in the geographical space, the so-called technical-scientific-informational environment. In Brazil, the distribution of technical infrastructure for the modernization of the country reveals a territorial heterogeneity derived from the strategies adopted by the State as well as industrial and financial capital. In this context of socio-spatial inequalities, the recently created Metropolitan Region of the Vale of Paraíba and Litoral Norte (RMVPLN), composed of municipalities whose characteristics are more or less representative of the current technological period, is discussed. This work analyzes the process of modernization of the RMVPLN, taking into considering the impacts of public policies directed at economic and technological development and which have been implemented over the past five decades.
\end{abstract}

Keywords: Economic modernization. Technical-scientific informational environment. Public policies.

\footnotetext{
${ }^{1}$ Universidade do Vale do Paraíba. Mestre em Planejamento Urbano e Regional pela Universidade do Vale do Paraíba (Univap), Bolsista Capes. Doutorando em Planejamento Urbano e Regional pela Universidade do Vale do Paraíba (Univap), Bolsista Capes. Av. Shishima Hifumi, 2911, Urbanova, São José dos Campos, SP, CEP: 12244-000. E-mail: joseandrade26@ yahoo.com.br ${ }^{2}$ Universidade do Vale do Paraíba. Professora do Programa de Pós-Graduação Stricto Sensu em Planejamento Urbano e Regional da Universidade do Vale do Paraíba (Univap). Av. Shishima Hifumi, 2911, Urbanova, São José dos Campos, SP, CEP: 12244-000. E-mail: adriane@univap.br
} 


\section{Introdução}

$\mathrm{O}$ atual período tecnológico tem origem na segunda metade do século $\mathrm{XX}$ e caracteriza-se, segundo Santos (2012), pela forte interação da técnica, ciência e informação, elementos responsáveis pelo surgimento de uma nova estrutura social e econômica, com implicações diretas no espaço geográfico, agora denominado meio técnico-científico-informacional.

Embora recente, a origem e configuração desse atual meio geográfico têm motivado análises por parte de estudiosos de diversas áreas, preocupados em compreender as rápidas mudanças vividas pela sociedade contemporânea.

Segundo Castells (2000, p. 43), após a década de 1970 iniciou-se nos Estados Unidos a formação de "um novo paradigma tecnológico" com reflexos nos aspectos sociais, econômicos e culturais. Segundo o autor, esse novo modelo tecnológico foi organizado com base no desenvolvimento da tecnologia da informação nesse país "em interação com a economia global e a geopolítica mundial, que concretizou um novo estilo de produção, comunicação, gerenciamento e vida".

No Brasil a modernização da economia e do território a partir de 1970 acelerou a consolidação do meio técnico-científico-informacional, em especial na região Sudeste, onde grande parte dos investimentos públicos e privados voltados à indústria incidiram e onde, atualmente, se concentra a maior densidade técnica do país. No entanto, como atestam Santos e Silveira (2013, p. 53), a concentração de objetos técnicos no Sudeste irradiou o meio técnico-científico-informacional para outras regiões do país, sendo possível identificar "áreas contínuas no Sudeste e no Sul ou constituindo manchas e pontos no resto do país".

É na região Sudeste, mais especificamente no estado de São Paulo que está a região do Vale do Paraíba. Ali, a exemplo de outros lugares, a formação do meio técnico-científico-informacional ocorreu em escalas e tempos diferenciados. As variações dos níveis de densidades técnicas encontradas na região revelam a heterogeneidade socioeconômica dos municípios que compõem a recém instituída Região Metropolitana do Vale do Paraíba e Litoral Norte (RMVPLN). Ao mesmo tempo que se forma um meio geográfico diferenciado pelas densidades técnicas, resultantes das ações governamentais, em especial daquelas que nas décadas de 1960 e 
1970 incentivaram o processo de industrialização, verificam-se os contrastes dos indicadores socioeconômicos entre os municípios da região.

Entre seus 39 municípios, alguns, como São José dos Campos, figuram entre os primeiros no estado de São Paulo quanto ao Produto Interno Bruto (PIB), Índice de Desenvolvimento Humano (IDH) e Desenvolvimento Científico e Tecnológico.

A consolidação da região como uma das mais importantes do país se deve a diversos fatores, entre os quais a forte participação do Estado na instalação de infraestrutura urbano-regional, em especial a construção da Rodovia Presidente Dutra, na década de 1950, bem como a criação de Instituições de Ensino e Pesquisa, como o Instituto Tecnológico de Aeronáutica (ITA), inaugurado em 1951, voltado para a formação de pessoal especializado na área de Engenharia Aeronáutica, o Centro Técnico de Aeronáutica (CTA), desde 2009, o Departamento de Ciência e Tecnologia Aeroespacial (DCTA) e o Instituto de Pesquisas Espaciais (Inpe), incentivando investimentos do capital industrial na região.

Na década de 1970, os Planos Nacionais de Desenvolvimento Econômico (PND I e II), revelam o projeto de modernização do território, pautados no desenvolvimento industrial e tecnológico. Nessa década, a desconcentração industrial proveniente da Grande São Paulo, encontrou no interior do estado condições propícias ao desenvolvimento industrial. A existência de um parque industrial diversificado e de Instituições de Ensino e Pesquisas contribuiu para a efetivação do processo de industrialização na região.

Nesse sentido, este trabalho dedica-se a analisar o processo de modernização da RMVPLN, considerando as políticas públicas voltadas ao desenvolvimento econômico e tecnológico, implementadas ao longo das últimas cinco décadas e seus reflexos na região.

\section{Metodologia}

A metodologia utilizada na elaboração desta pesquisa incluiu a leitura de textos de autores como Santos (1996, 2005, 2012), Castells (2000), Lencioni (1998), Becker e Egler (2003) e Costa (1982). A partir desses estudos buscou-se compreender a origem e as características da atual configuração espacial denominada meio técnico-científicoinformacional. Buscou-se ainda verificar a atuação do Estado brasileiro no processo de 
modernização do território e o surgimento de novas configurações territoriais, enfatizando as ações governamentais no período militar.

Para a concepção dos mapas aqui apresentados, foi utilizado o software ArcGis, que, a partir de uma base cartográfica digital disponibilizada pelo Instituto de Brasileiro de Geografia e Estatísticas (IBGE), possibilitou a sobreposição de informações georreferenciadas de alguns tipos de infraestrutura urbana existentes na RMVPLN, tais como: rodovias, ferrovias, portos e aeroportos. Para esse mapeamento, foi também considerada a distribuição das indústrias de base tecnológica da região.

Para o mapeamento dos pontos de estações de telefonia móvel, foram utilizados dados de 2014 da Agência Nacional de Telecomunicações (Anatel) referentes às coordenadas geográficas das estações de Serviço Móvel Pessoal (SMP). Com o uso de recursos do ambiente de Sistema de Informação Geográfica (SIG) foi possível espacializar as estações de telefonia móvel na região. Com base na vetorização automática dos referidos pontos foi realizada a análise espacial por densidade Kernell. Tais procedimentos permitiram identificar os diferentes níveis de densidade técnica existentes na RMVPLN. ${ }^{3}$

\section{Aspectos da modernização do território brasileiro e da formação do meio técnico-científico informacional}

Entender os processos que originaram o meio técnico científico informacional só é possível mediante a realização de uma análise da evolução das técnicas. É preciso ainda entender que desde a pré-história, como modo de se proteger e de buscar alimentos, o homem desenvolve técnicas e instrumentos. Porém, neste estudo, privilegia-se a análise do período que se inicia com a Primeira Revolução Industrial, quando, segundo Santos (2012), tem início o “tempo das máquinas”, a partir do qual um novo modelo social, econômico e cultural é instituído. Para Santos (2012, p. 172),

O papel que as técnicas alcançaram, através da máquina, na produção da história mundial, a partir da revolução industrial, faz desse momento um marco definitivo. É também, um momento de grande aceleração, ponto de partida para transformações consideráveis.

\footnotetext{
${ }^{3}$ Informaç̃es sobre o método ora descrito podem ser encontradas em Andrade, Dória e Gonçalves (2012).
} 
No século XX, logo após a Segunda Guerra Mundial, tem início o que Radovan Richta denominou de período técnico-científico. Os reflexos dos sistemas técnicos do período em questão englobam, segundo Santos (2012, p. 176), “formas de produzir energia, bens e serviços, formas de relacionar os homens entre eles, formas de informação, formas de discurso e interlocução".

Denominado período técnico-científico-informacional, o atual período caracteriza-se pelo desenvolvimento de sistemas técnicos voltados à informação. Iniciado no final da década de 1970, a análise desse período permite entender o modo como tais sistemas vêm sendo facilmente incorporados à estrutura social e econômica. Porém, como atesta Santos (2012), a abrangência da incorporação desses sistemas pela sociedade é limitada. Para o autor (2012, p. 179), tal limitação ocorre em função da “divisão do trabalho e pelas condições de criação de densidade. Quanto mais forte, numa área, é a divisão do trabalho, tanto mais há tendência para que esses sistemas técnicos hegemônicos se instalem".

A partir da década de 1970, os objetos técnicos - criados para o aumento da fluidez da informação -, implantados passam a dar origem a novas configurações territoriais. De acordo com Santos (2005, p. 38) o território,

é marcado pela presença da ciência e da técnica nos processos de remodelação do território essenciais às produções hegemônicas que necessitaram desse meio geográfico para a sua realização. A informação, em todas as suas formas, é o motor fundamental do processo social e o território e, também, equipado para facilitar a sua circulação.

No contexto mundial, a tecnologia da informação proporcionou a organização de um novo modelo espacial, criando uma nova divisão espacial do trabalho, com o acréscimo da variável tecnológica. De acordo com Castells (1998 apud BENKO, 1999, p. 127), as indústrias de alta tecnologia da informação apresentam

localização das funções de criação da informação, que controlam toda uma cadeia de interdependências, em lugares que gozam de potencial técnico e científico de alto nível e de meio inovador (universidades de qualidade, centros de pesquisa e desenvolvimento universitários, públicos e privados, sinergias entre as diferentes instituições, fontes de venture capital de alto risco).

A partir da década de 1970, as alterações provenientes do uso da informação e das técnicas que a viabilizam, no contexto espacial e social, atingem grande parte dos 
territórios. Acompanhando a tendência mundial, no Brasil as mudanças de ordem territorial e social ocorrem via modernização econômica e de infraestrutura urbana, culminando na formação em parte de seu território de um meio modernizado.

Nessa década, a exemplo do constatado por Santos (2005) e Becker e Egler (2003), são implantadas as "próteses" que possibilitarão o aumento da fluidez no espaço e o maior dinamismo das relações econômicas e sociais no país e deste com o mundo. Além de investimentos destinados à pavimentação e à construção de rodovias, ocorrerá a modernização e a implantação de novos aeroportos, portos e ferrovias, com vistas à integração econômica territorial. Nesse processo de avanço das infraestruturas técnicas, denominadas "fixos" por Santos (2005), deve ser ressaltado o desenvolvimento, também estratégico, do setor de telecomunicações.

O I PND e o II PND elaborados na década de 1970 revelam o projeto governamental de investimento setorial. Dentre os setores previstos nesses planos são citados os de transportes, energia elétrica, produção de combustíveis, além do desenvolvimento científico e tecnológico voltado a setores estratégicos como o aeroespacial.

Nesse contexto e considerando os modernos sistemas de engenharia implantadas no território, percebe-se um país no qual coexistem áreas de maior e menor concentração de infraestrutura técnica, e, por isso, uma expressiva manifestação da divisão social do trabalho. Santos (2005) constata a existência de uma grande área com características representativas do meio técnico científico-informacional. Denominada pelo autor de Região Concentrada, tal área compreende os estados de São Paulo, Rio de Janeiro, Paraná, Santa Catarina, Rio Grande do Sul e partes dos estados do Mato Grosso do Sul, Goiás e Espírito Santo, os quais constituem a macrorregião do Centro-Sul do país.

Sobre a região Sudeste diversos estudos afirmam ser ela o lócus urbanoindustrial e de maior concentração de infraestrutura técnica. Para Becker e Egler (2003), os empreendimentos nessa região ocorreram com a participação efetiva do Governo Federal, o qual direcionou recursos provenientes da agricultura para esse fim. Continuando esses autores, eles esclarecem que, apesar dos esforços dos demais estados, foi para o estado de São Paulo que grande parte das políticas e dos investimentos foi direcionada. 
A maioria dos investimentos governamentais - em indústria, transporte e energia - foi para o Sudeste devido aos compromissos assumidos com os interesses desses Estados. As corporações estrangeiras favoreceram a localização na área metropolitana de São Paulo e nas suas vizinhanças, enquanto o Rio de Janeiro - lócus da maioria das companhias estatais - experimentou um pronunciado declínio. (BECKER; EGLER, 2003, p. 86-87)

Porém, segundo Souza (2008), já a partir da década de 1960, por meio de um planejamento estratégico que visava a descentralização econômica a partir da cidade de São Paulo, inicia-se o processo de interiorização industrial. Apesar do objetivo de estender a atividade industrial para outras regiões do país, o processo de industrialização será intensificado no próprio interior do estado de São Paulo, onde municípios como Campinas, São José dos Campos e Sorocaba rapidamente se tornam importantes centros da produção industrial. Esse processo que manteve e intensificou a produção industrial no estado de São Paulo, Costa (1982 apud Souza, 2008, p. 34) denomina "descentralização concentrada".

O mesmo processo é analisado por Lencioni (1998), que constata um movimento de reestruturação urbano-industrial da metrópole de São Paulo como reflexo da dispersão das atividades industriais em direção ao interior do estado. A capital, segundo a autora (1998 apud Souza, 2008, p. 34), torna-se o "centro de comando das atividades industriais desenvolvidas no interior do estado, sobretudo nos municípios correspondentes às regiões administrativas do Vale do Paraíba, Sorocaba, Campinas, Ribeirão Preto e Bauru".

De acordo com Souza (2008), a interiorização das atividades industriais manteve o nível de produção do estado de São Paulo. De acordo com a autora (2008, p. 35), nesse estado,

a região do Vale do Paraíba será lugar de investimentos públicos, com vistas na formação de um centro da indústria bélica nacional. A busca pela autonomia tecnológica inseriu a região - localizada entre as duas principais metrópoles nacionais -, no contexto de lugares aptos ao desenvolvimento científico e tecnológico de setores estratégicos, no caso, do aeronáutico e de armamentos.

Atualmente, sob o formato de uma nova unidade político-administrativa, respectiva à RMVPLN, o Vale do Paraíba revela seu papel estratégico voltado para o desenvolvimento de diversos setores produtivos, entre os quais destacam-se o aeroespacial, o petroquímico, as telecomunicações e o de eletrônicos. Sobre o setor 
aeroespacial, deve-se ressaltar o município de São José dos Campos, centro da produção científica, tecnológica e industrial do setor no país.

\section{Modernização das infraestruturas técnicas e a produção científica, tecnológica e industrial na RMVPLN}

Instituída em 2012 pelo governo do estado de São Paulo, Lei Complementar $\mathrm{n}^{\circ}$ 1.166, a Região Metropolitana do Vale do Paraíba e Litoral Norte (RMVPLN) é composta por 39 municípios localizados na área da Bacia do Rio Paraíba do Sul, em área litorânea, e nas regiões serranas no extremo leste do estado de São Paulo. Sua localização privilegiada permite acesso às regiões metropolitanas de São Paulo e do Rio de Janeiro, bem como à região sul do estado de Minas Gerais (Figura 1).

Dados do IBGE (2010) revelam que a RMVPLN possui 2.264,594 habitantes, sendo São José dos Campos, com 629.921 habitantes, o mais populoso, e Arapeí, com 2.493 habitantes, o menos populoso. Sobre o Produto Interno Bruto (PIB) da RMVPLN, dados do IBGE mostram o valor de R\$ 61.698.188,00 em 2010, sendo São José dos Campos o município que apresentou o maior PIB, com $\mathrm{R} \$ 24.117 .145,00$, seguido por Taubaté, com R \$ 9.778.529,00, e Jacareí, com R \$ 5.661.582,00.

Na década de 1950, no país, as políticas públicas versaram a favor do rodoviarismo, deixando de lado as ferrovias. A construção e pavimentação de rodovias expressam a atuação governamental no sentido de promover o desenvolvimento do setor automobilístico no país. Com esse objetivo, gradativamente o transporte rodoviário foi ganhando destaque em detrimento do ferroviário.

É nesse contexto que a partir da década de 1950 a Região do Vale do Paraíba Paulista passou por importantes mudanças, a começar pela inauguração, em 1951, da Rodovia Presidente Dutra que terá um importante papel na articulação entre São Paulo e Rio de Janeiro, os principais centros econômicos e de produção industrial do país. A Dutra, como é chamada pelos moradores do Vale do Paraíba, interligou municípios e promoveu significativas mudanças de âmbito econômico na região.

Na década de 1970, o I PND sinalizou a intenção governamental em efetivar a integração nacional, por meio da criação de novas rodovias e melhoramentos de algumas já existentes. Na região, a modernização da Rodovia Tamoios exercerá importante papel, ao efetivar a articulação entre os municípios do Vale do Paraíba ao 
Litoral Norte do estado de São Paulo. Em 2012, iniciaram-se as obras de ampliação da Rodovia Tamoios, a fim de atender as demandas do setor petroquímico e ampliar o acesso ao Porto de São Sebastião. Além da Rodovia Tamoios, a Rodovia Federal RioSantos liga o Litoral Norte ao município de Santos e a cidade do Rio de Janeiro.

\section{Figura 1 - Localização da RMVPLN}

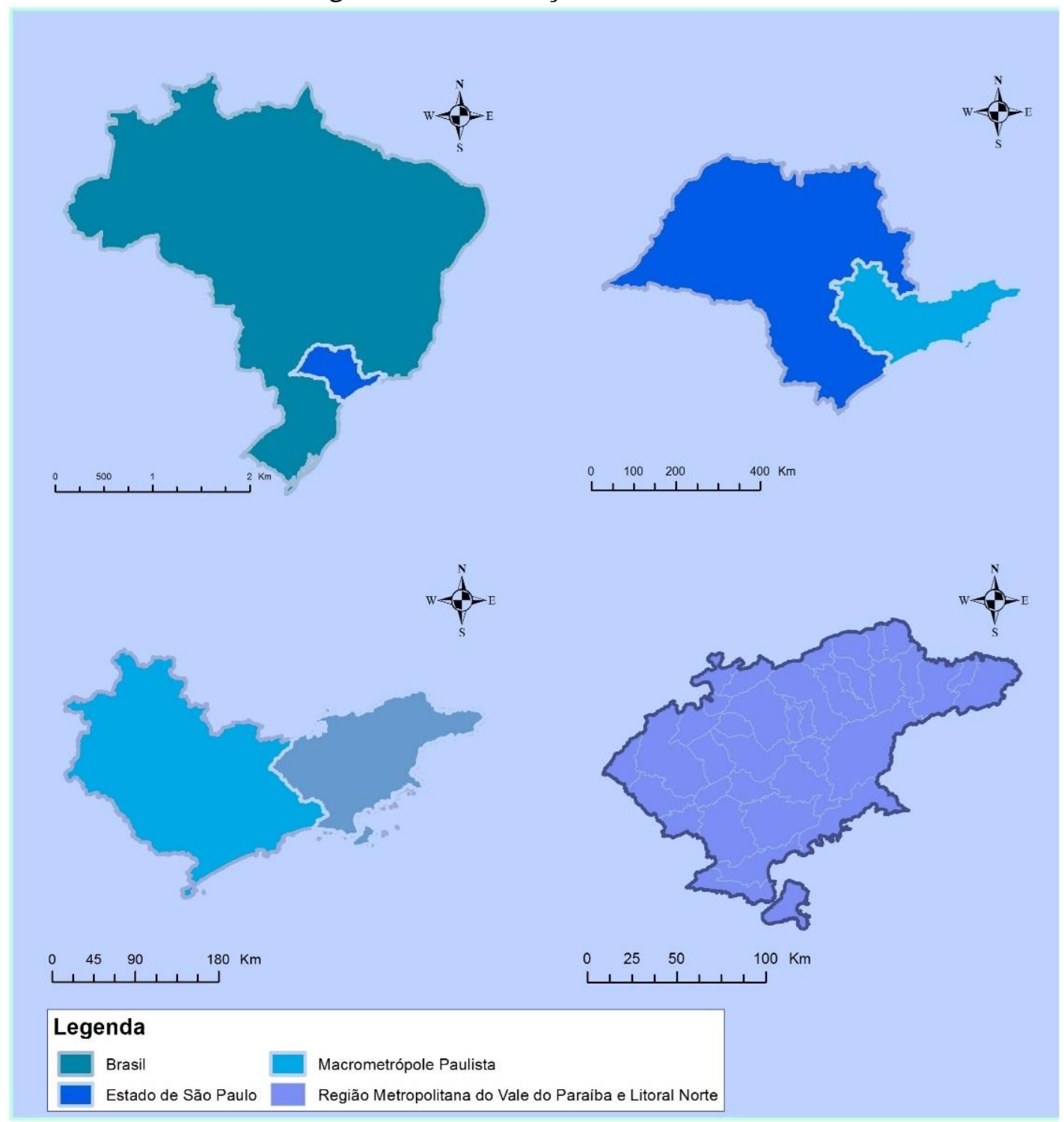

Fonte: elaborada pelos autores com base em dados do IBGE (2010).

Atualmente, eixos rodoviários complementam o acesso da Região do Vale do Paraíba à cidade de São Paulo, como é o caso das rodovias Ayrton Senna e Carvalho Pinto, sendo esta última, também, uma importante via de acesso aos municípios da Serra da Mantiqueira.

Como parte de um projeto que visava a autonomia tecnológica do setor aeroespacial no país, em 1951 foram inaugurados, no município de São José dos 
Campos, o Centro Técnico de Aeronáutica (CTA) e, desde 2009, o Departamento de Ciência e Tecnologia Aeroespacial (DCTA), uma instituição de ensino destinada à formação de pessoal especializado na área de Engenharia Aeronáutica. No terreno de $9.280 .000 \mathrm{~m}^{2}$ doado pelo município ao Ministério da Aeronáutica foi instalado um aeroporto que mais tarde, na década de 1970, após a criação da Empresa Brasileira de Aeronáutica S.A. (EMBRAER), passou por reformas, como o asfaltamento e ampliação da pista. Dados da Empresa Brasileira de Infraestrutura Aeroportuária (INFRAERO) mostram que atualmente o aeroporto Professor Urbano Ernesto Stumpf, além de atender a programas militares, sua vocação inicial, possui capacidade para pouso e decolagem de aviões cargueiros, bem como de passageiros.

Em São Sebastião, município da região litorânea da RMVPLN, está instalado o Porto de São Sebastião. Inaugurado em 1955, atualmente o Porto de São Sebastião possui capacidade de armazenagem e escoamento de cargas variadas, que incluem veículos, minérios e cereais e um terminal de uso exclusivo da empresa Petróleo Brasileiro S.A. (Petrobras), para o transporte de óleo, derivados de petróleo e álcool combustível. Em 1980, foi inaugurada em São José dos Campos a Refinaria Henrique Lage (REVAP) da Petrobras. Segundo Souza (2008, p. 53), tratava-se de um "importante empreendimento estatal, que consolidou a cidade, também, no setor petroquímico". Continuando, Souza (2008, p. 53) esclarece que "a refinaria começou a ser construída em 1974, cumprindo uma das metas do II PND, que era de suprir a demanda dos estados de São Paulo, Mato Grosso do Sul e partes dos estados de Minas Gerais e Paraná, em relação aos derivados de petróleo".

Dados da página institucional da Petrobras revelam que, desde a sua inauguração, a Refinaria Henrique Lage passou por adaptações e modernização a fim de se adequar as normas de qualidade brasileiras e internacionais. Um dos investimentos mais recentes foi o realizado pelo Governo Federal via o Programa de Aceleração do Crescimento (PAC) 2, para a implantação de dutos e gasodutos entre a região da Bacia do Rio Paraíba e o litoral.

A disposição da infraestrutura de transportes e do setor petroquímico instalada na RMVPLN pode ser visualizada na Figura 2. 
Figura 2 - Infraestruturas do setor de transportes e petroquímico na RMVPLN

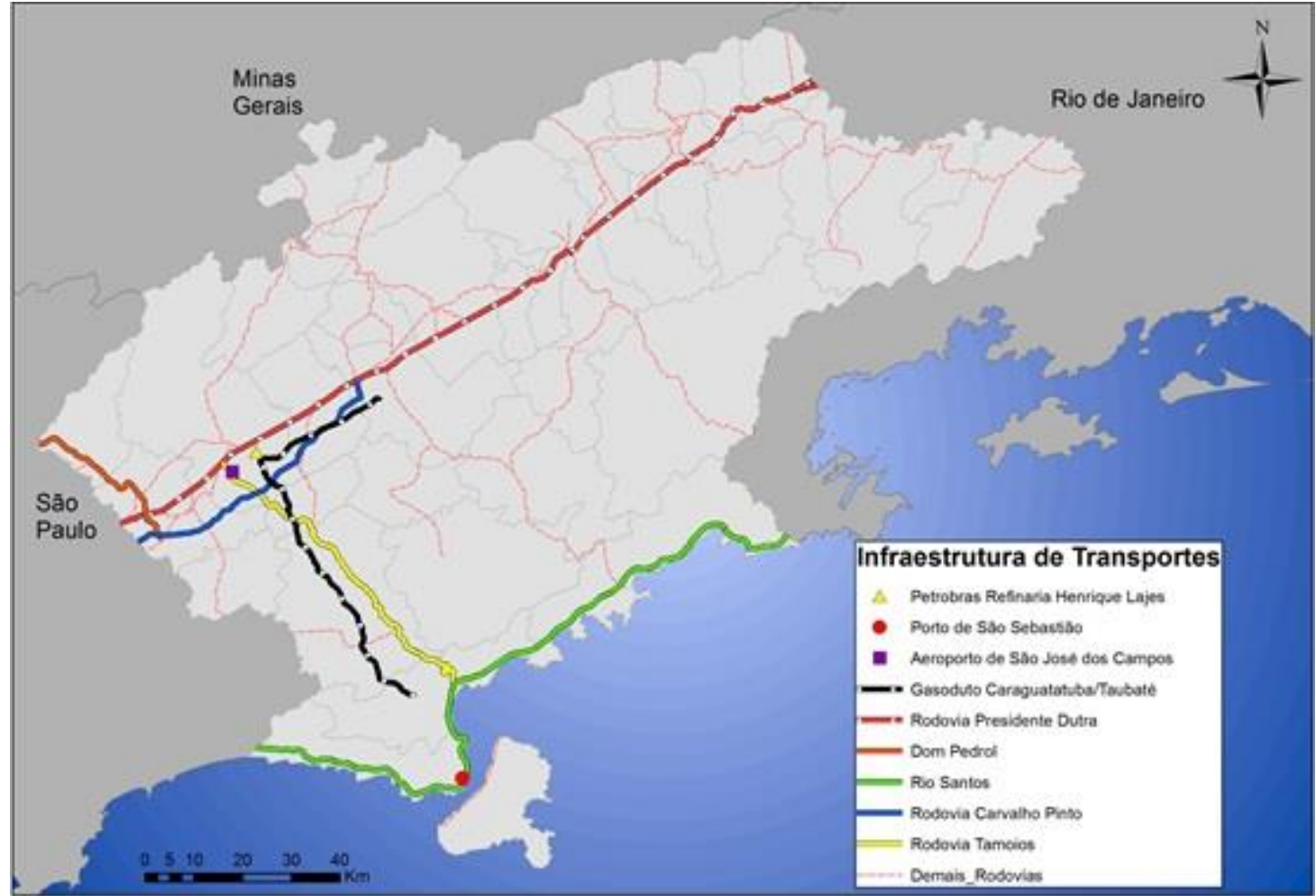

Fonte: elaborada pelos autores com base nos dados de DNIT (2013), INFRAERO (2014) e PETROBRAS (2006).

Ao longo das três últimas décadas o mundo assistiu a uma revolução do setor de telecomunicações, impulsionada pelos avanços da eletrônica. No Brasil, com a privatização do setor de telecomunicações ocorrida em 1997, os segmentos de telefonia móvel e de internet banda larga incorporaram uma concorrência entre empresas estrangeiras, interessadas na cobertura do território nacional e na conquista do potencial mercado consumidor brasileiro. ${ }^{4}$

A distribuição das torres de telefonia móvel na RMVPLN mostra que todos os municípios são servidos por essa tecnologia, com duas áreas, respectivas aos municípios de São José dos Campos e Taubaté, em que a densidade quando à existência de torres é a maior da região (Figura 3).

\footnotetext{
${ }^{4}$ Dados da Agência Nacional de Telecomunicações (ANATEL) para o ano de 2014 revelam que o estado de São Paulo possui 39.280 torres de telefonia celular, sendo $27,71 \%$, ou 10.886 , das torres instaladas nas quatro regiões metropolitanas do estado. Desse total, 19,39\% encontram-se instaladas na região metropolitana de São Paulo, que possui 7.616 torres; seguida pela RMVPLN, cujo total de torres é de 1.309 , ou seja, 3,33\%; pela região metropolitana de Campinas, com 1.150 torres, equivalendo a $2,93 \%$ e pela região metropolitana da Baixada Santista, que possui 811 torres, ou seja, 2,06\% do total existente no estado.
} 
Figura 3 - Espacialização das estações de telefonia móvel na RMVPLN

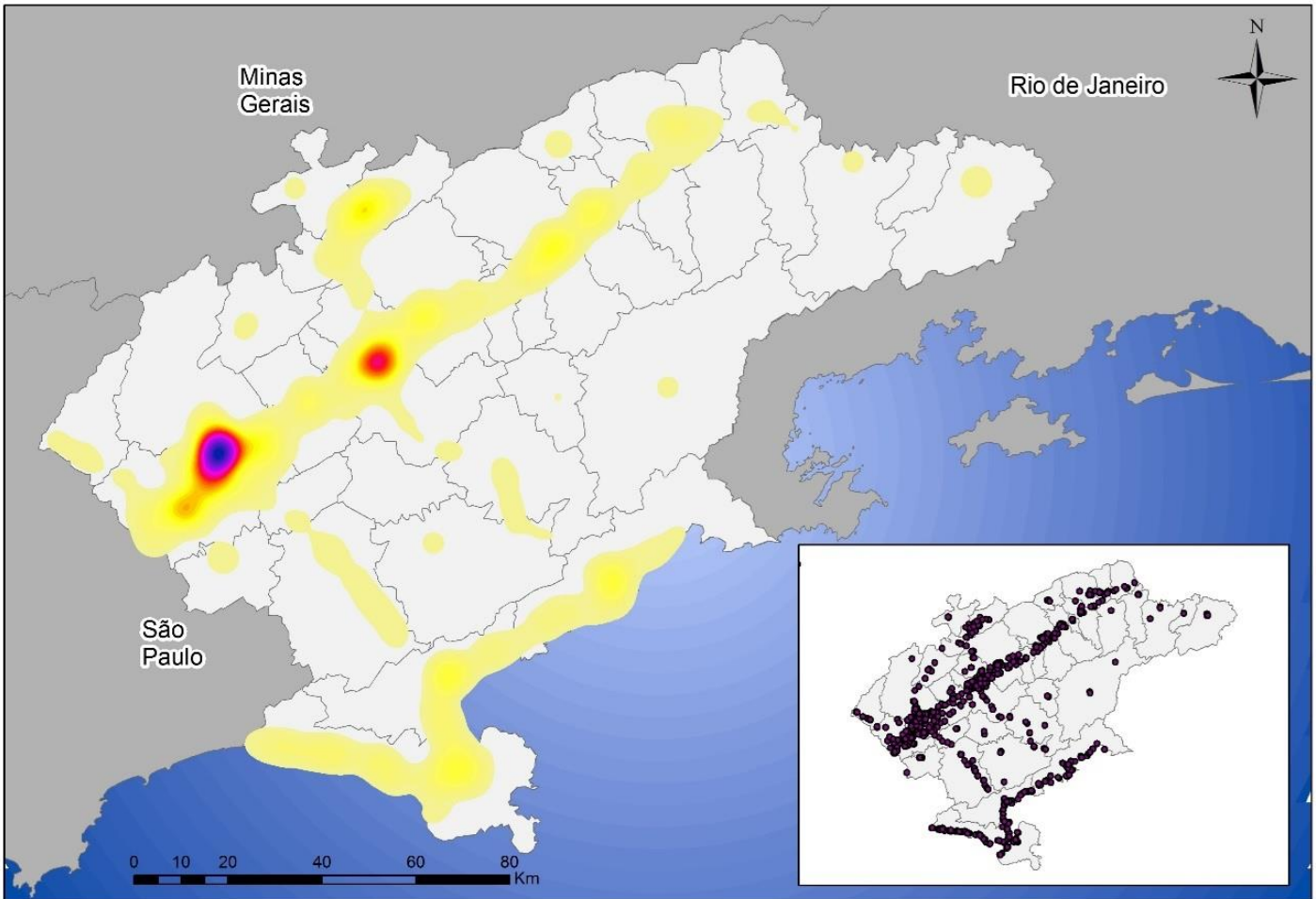

Fonte: elaborada pelos autores com base em dados da ANATEL (2014).

$\mathrm{Na}$ evolução do setor de telecomunicações no Brasil, é importante ressaltar as iniciativas privadas na criação de redes de conexão de internet de alta velocidade. Com esse objetivo, foram implantadas nas grandes cidades ou metrópoles as Redes Metropolitanas. Segundo Toledo Junior (2003, p. 103), no final da década de 1990, "as novas infraestruturas de telecomunicações foram implantadas no centro da cidade de São Paulo concomitantemente por diversas empresas privadas, tais como a Embratel, a MetroRED, a Netstream, e a Pegasus".

Essas redes de alta velocidade são produtos comercializados por empresas privadas no intuito de oferecer, com uso de cabos de fibra óptica, altas velocidades de transmissão e recepção de dados. De acordo com a página eletrônica da empresa administradora da rede metropolitana Megatelecom (2013), entre outras empresas localizadas na RMVPLN está a EMBRAER.

Informações encontradas no Atlas Brasileiro de Telecomunicações para o ano de 2013 mostram que o município de São José dos Campos abriga duas redes metropolitanas (Figura 5). 
Outro referencial de modernização da RMVPLN é a existência de importantes instituições de ensino e pesquisa. Nesse contexto, merecem ser destacados os institutos que compõem o DCTA, localizado na cidade de São José dos Campos.

Figura 4 - Redes metropolitanas de internet de alta velocidade na RMVPLN

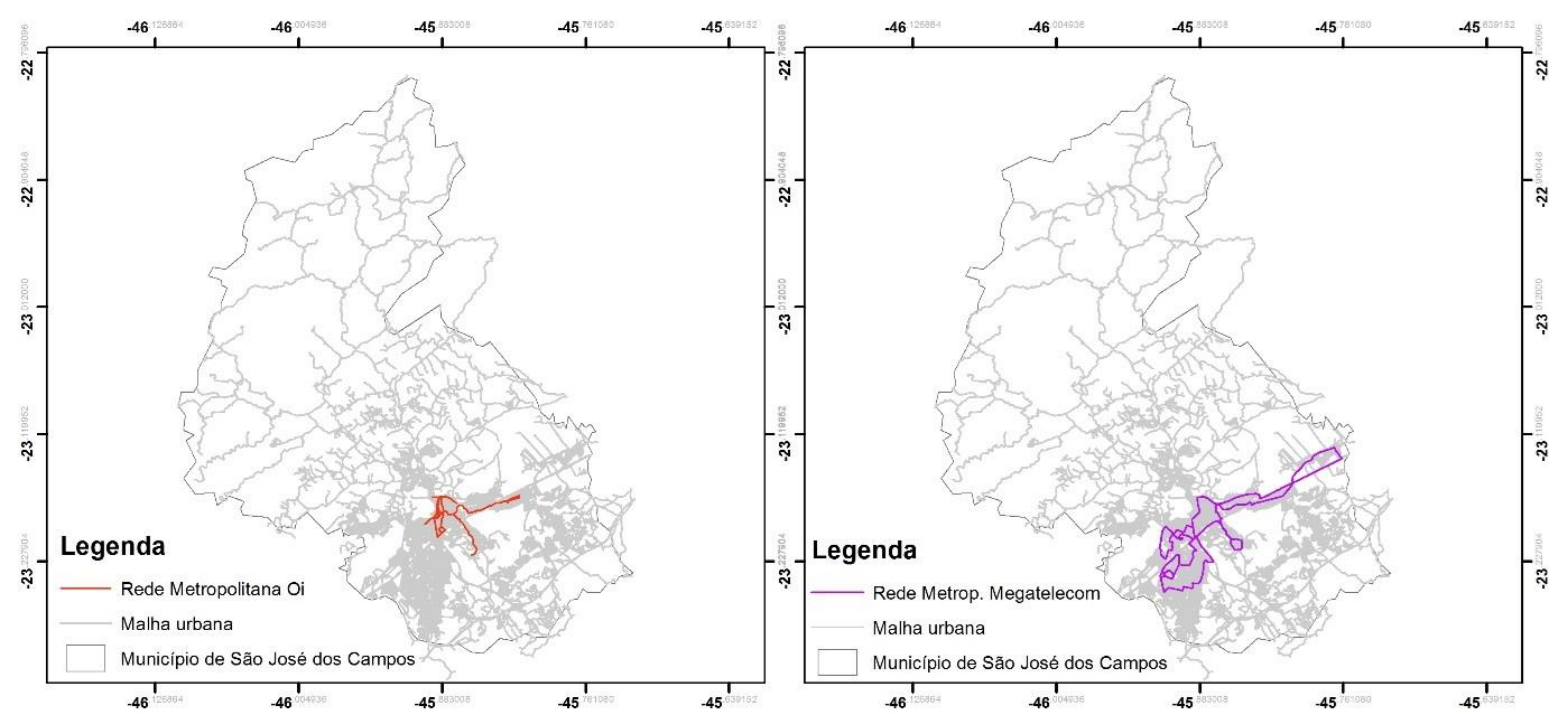

Fonte: elaborada pelos autores com base em dados do Atlas Brasileiro de Telecomunicações (2013).

O ITA, reconhecido pela formação de cientistas e engenheiros, pela introdução da pós-graduação na área de Engenharia no ensino brasileiro e pela criação de empresas como a EMBRAER DCTA, possui Instituto de Fomento e Coordenação Industrial (IFI), responsável pela coordenação e apoio ao desenvolvimento da indústria aeroespacial; o Instituto de Estudos Avançados (IEAv), responsável pelo desenvolvimento de estudos e pesquisas nas áreas de Aerotermodinâmica e Hipersônica, Energia Nuclear, Física Aplicada, Laser e Sensoriamento Remoto, e o Instituto de Atividades Espaciais (IAE) que integra atividades de pesquisa e desenvolvimento ligadas tanto à área de Ciências Espaciais como à Aeronáutica.

O INPE integra o grupo de instituições de ensino e pesquisa localizadas em São José dos Campos. Desde a sua criação, em 1961, firmou sua importância como instituição de pesquisa nas áreas de Ciências Espaciais e Atmosféricas; Ciências Ambientais e Meteorológicas, e Engenharia e Tecnologias Espaciais. Segundo Souza (2008, p. 166),

Por meio das pesquisas desenvolvidas pela instituição, o País hoje integra um grupo de países de credibilidade na discussão de questões de interesse mundial respectivas às mudanças climáticas e ao aquecimento global. A partir de dados sobre o desmatamento da 
Amazônia - também de interesse mundial -, o INPE participa da definição e da implementação de ações governamentais relacionadas ao problema e, mediante a precisão dos dados oferecidos pela Instituição, o governo brasileiro demonstra ao mundo competência no tratamento da questão.

A vocação da RMVPLN para o desenvolvimento de atividades voltadas à pesquisa científica e ao desenvolvimento tecnológico pode ainda ser constatada, se considerada a existência de instituições como a Universidade do Vale do Paraíba (UNIVAP) e o seu Instituto de Pesquisa e Desenvolvimento, responsável por pesquisas na área de Bioengenharia, Física e Astronomia, Ciências Biológicas, Engenharia Biomédica, Planejamento Urbano e Regional, entre outros; a Faculdade de Engenharia de Guaratinguetá, criada na década de 1960 e incorporada à Universidade Estadual Paulista "Júlio de Mesquita Filho" na década de 1970, responsável pela formação na área de Engenharia Mecânica e de Materiais; a Faculdade de Engenharia Química de Lorena criada em 1970 e incorporada em 2006 à Universidade de São Paulo (USP) sob a nomenclatura de Escola de Engenharia de Lorena da Universidade de São Paulo, onde ocorre a formação na área de Engenharia Química e pesquisas na área, e ainda a Universidade de Taubaté, importante instituição de ensino da região.

A existência dessas instituições, aliada ao processo de interiorização das atividades industriais a partir da cidade de São Paulo, contribuirá para o desenvolvimento de políticas públicas na região do Vale do Paraíba, em especial, a contida no II PND, cuja proposta era o desenvolvimento científico e tecnológico no país. Sobre essa questão Souza (2008, p. 35) esclarece que

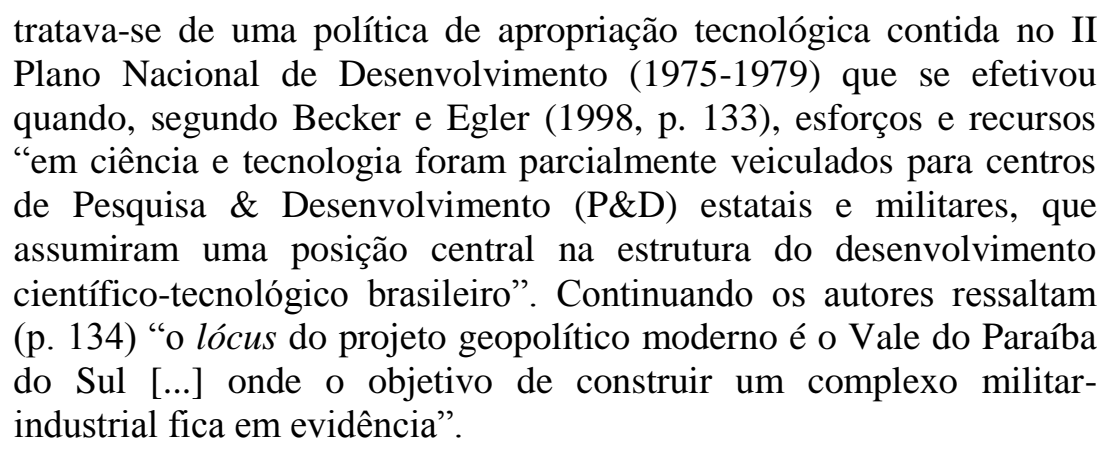

Com o incentivo político, diversas empresas do segmento aeroespacial foram criadas na região. Por abrigar a EMBRAER, sede do segmento no país e toda a infraestrutura, no que se refere aos institutos do DCTA e ao INPE voltados à formação profissional e à pesquisa e desenvolvimento tecnológico para o setor, concentrará sempre um número maior de empresas do segmento se comparada ao demais 
municípios da região. De acordo com os dados do Catálogo de Empresas do Setor Aeroespacial (CESAER) e da Associação das Indústrias Aeroespaciais do Brasil (AIAB), em 2013, a RMVPLN possuía 92 empresas do setor aeroespacial, das quais 68 estavam localizadas no município de São José dos Campos, oito em Jacareí, seis em Taubaté, três em Caçapava, duas em Jambeiro e uma em Cruzeiro, Guaratinguetá, Lorena, Pindamonhangaba e Tremembé.

Como comprovado por Souza (2008), a partir da década de 1950, um conjunto de fatores contribuirá para que em São José dos Campos o processo de industrialização se desenvolva com uma especial participação do setor aeroespacial. Porém, ao longo do mesmo processo na RMVPLN, diversos outros segmentos produtivos serão implementados.

De acordo com o Estudo Técnico de 2011 da Empresa Paulista de Planejamento Metropolitano S.A. (EMPLASA), além do setor aeroespacial em São José dos Campos, a indústria, nomeadamente, a General Motors do Brasil Ltda., a Refinaria Henrique Lage da Petrobras e a Johnson \& Johnson S/A, representa os segmentos automobilístico, petroquímico e farmacêutico.

No município de Taubaté, o segundo mais industrializado da RMVPLN, os setores de eletrônicos, metalurgia, produção de veículos e peças e de bebidas são representados pelas empresas LG Electronics, Usinas Siderúrgicas de Minas Gerais S/A. (USIMINAS), Volkswagen do Brasil e a Ford Brasil.

Em Jacareí o segmento industrial de maior importância é o de papel e celulose, representado pela empresa Fibria Celulose, seguido pelo setor de produção de bebidas, com a Companhia de Bebidas das Américas (AmBev).

Também no trecho mais industrializado da RMVPLN, encontra-se o município de Caçapava, cujo setor de maior expressão é o alimentício representado pela empresa suíça Nestlé S.A. Já em Pindamonhangaba, destaca-se o segmento de metalurgia representado pela Gerdau S.A.

$\mathrm{Na}$ região litorânea da RMVPLN, os municípios de São Sebastião e Caraguatatuba possuem unidades e infraestruturas que atendem a Petrobras, como a de escoamento e armazenamento de petróleo e gás a partir do Porto de São Sebastião e de tratamento de gás em Caraguatatuba. 
Com base em informações obtidas no Catálogo de Empresas do Setor Aeroespacial (CESAER/2013), na página eletrônica da Associação das Indústrias Aeroespaciais do Brasil (AIAB) e da Empresa Paulista de Planejamento Metropolitano S.A. (EMPLASA), constata-se a predominância do setor aeroespacial sobre os segmentos produtivos desenvolvidos na região. Porém, como já esclarecido, na RMVPLN, ainda que em menor número, diversos segmentos são contemplados, a exemplo do petroquímico, de metalurgia, de papel e celulose e de alimentos e bebidas (Figura 5).

Figura 5 - Principais segmentos industriais na RMVPLN

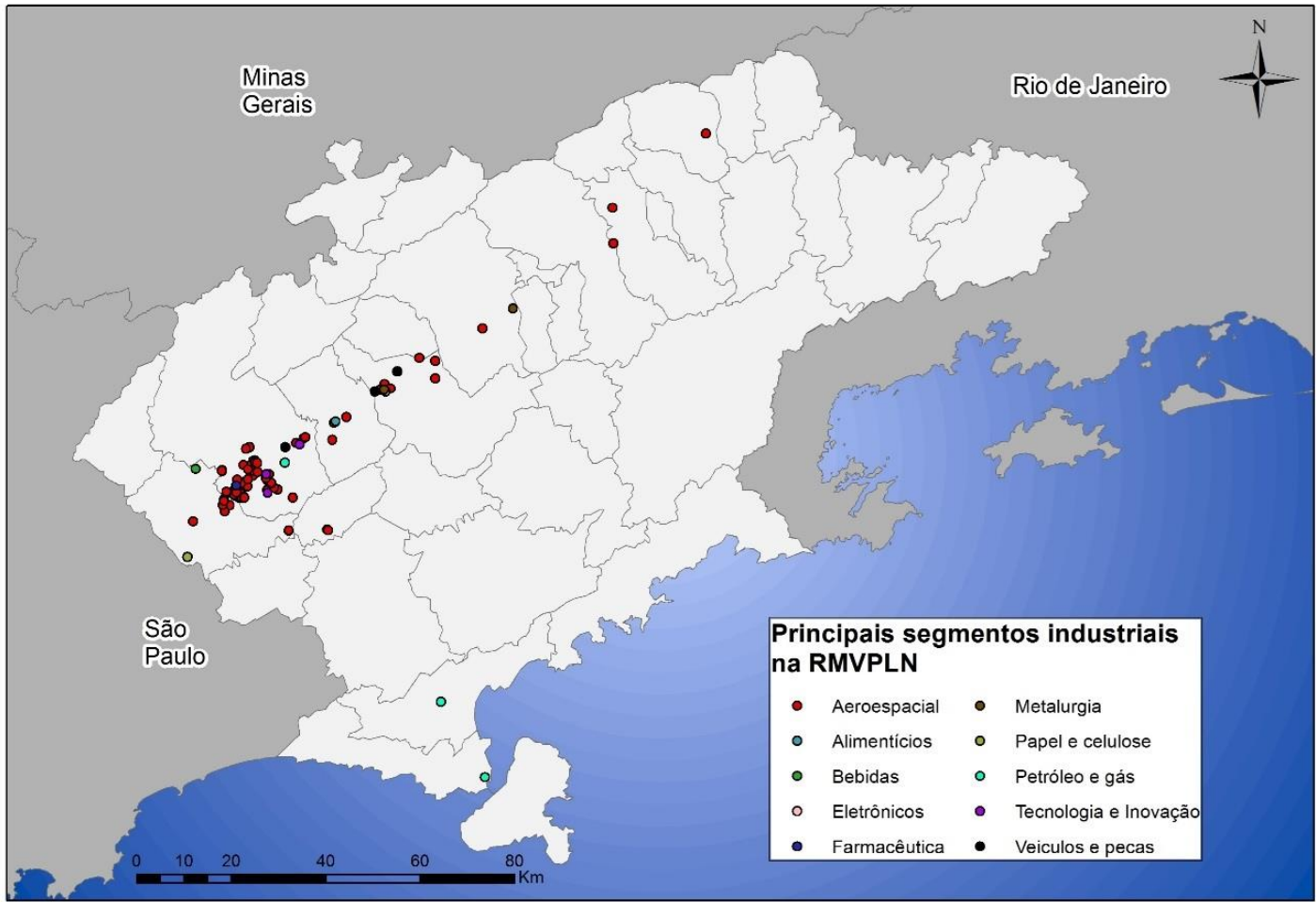

Fonte: elaborada pelos autores com base em dados da EMPLASA (2011), CESAER (2013) e AIAB (2013).

\section{Considerações finais}

Como não atinge todos os lugares e grupos sociais, aliado ao processo de globalização, as desigualdades socioeconômicas e espaciais tornam-se mais evidentes, gerando um meio geográfico, atualmente conhecido como meio técnico-científicoinformacional, heterogêneo quanto à composição quantitativa e qualitativa dos subespaços que o compõem. Nesse processo, o mundo se conforma no que Santos (1996, p. 51) denomina de "áreas de densidade (zonas luminosas), áreas praticamente vazias (zonas opacas) e uma infinidade de situações intermediárias estando cada 
combinação à altura de suportar as diferentes modalidades do funcionamento das sociedades em questão".

Alguns fatores condicionantes da formação do meio técnico-científicoinformacional descritos neste estudo sobre a Região Metropolitana do Vale do Paraíba e Litoral Norte foram ocasionados pela ação do Estado, ainda na década de 1950, quando, em busca da autonomia tecnológica do setor aeroespacial, implantou em São José dos Campos o DCTA e, neste, o ITA, ocasionando mudanças significativas no município e na região do Vale do Paraíba.

Na década de 1970, o projeto de modernização tecnológica e científica empreendido pelo Governo Federal é efetivado com o I PND e II PND. Em busca da integração territorial, a região, que já possuía a Rodovia Presidente Dutra para o acesso aos principais centros econômicos do país, São e Paulo e Rio de Janeiro, é atingida pelos investimentos governamentais em obras de infraestrutura rodoviária com a construção e o melhoramento de rodovias na região, como é o caso da Rodovia dos Tamoios, ligando os municípios do Vale do Paraíba ao Litoral Norte do estado de São Paulo, bem como as Rodovias Ayrton Senna e Carvalho Pinto, que promoverão o maior contato no interior da RMVPLN e com a cidade de São Paulo. Deve-se ressaltar, ainda, o projeto militar de desenvolvimento de setores estratégicos, como o aeronáutico e bélico, envolvendo instituições de ensino e pesquisa e empresas da região.

Na mesma década, o processo de descentralização da indústria a partir da Grande São Paulo na região do Vale do Paraíba encontrará na região as condições necessárias à efetivação do processo de industrialização, entre as quais a já existente Rodovia Presidente Dutra e a facilidade de escoamento da produção industrial.

Nesse contexto, verificou-se que em municípios próximos ao eixo da Rodovia Presidente Dutra, como São José dos Campos, Taubaté, Jacareí e Pindamonhangaba, considerados núcleos urbanos de elevado potencial econômico, e ainda em municípios do eixo viário Rio-Santos no Litoral Norte que apresentaram nas últimas duas décadas significativo crescimento econômico estão os mais elevados níveis de densidade técnica, informacional e comunicacional da região.

As recentes políticas de desenvolvimento econômico e social, a exemplo do PAC, vem promovendo profundas alterações quanto à infraestrutura urbana e regional 
em municípios da região litorânea da RMVPLN, como é o caso de Caraguatatuba e São Sebastião. De acordo com a EMPLASA (2011, p. 22), mudanças estão ocorrendo no Litoral Norte, transformando algumas cidades em "centros urbanos articulados e com dinâmica econômica concentrada nas atividades de petróleo e gás e forte potencial de inovação tecnológica, ativos ambientais e atividade turística".

Este artigo é parte de uma dissertação, ainda em processo de elaboração, intitulada Desenvolvimento regional e o meio técnico-científico-informacional: uma análise dos contrastes socioeconômicos e espaciais da Região Metropolitana do Vale do Paraíba e Litoral Norte, cujo objetivo principal é analisar o desenvolvimento regional e o meio técnico-científico-informacional, considerando os contrastes socioeconômicos e espaciais na Região Metropolitana do Vale do Paraíba e Litoral Norte.

Nesse sentido, além de identificar na RMVPLN os municípios cujas características são as mais representativas do atual período tecnológico, pretende-se, com a dissertação, responder a questões como: a) De que modo as políticas de modernização econômica e territorial adotadas pelo Governo Federal ao longo das últimas décadas repercutiram favoravelmente para a sociedade quanto à geração de empregos e à melhoria na qualidade de vida? e b) Considerando que a informação, via as novas tecnologias, é determinante para a inclusão social, quais são as iniciativas governamentais para esse fim?

\section{REFERÊNCIAS}

AIAB. Material Institucional. Disponível em: <http://www.aiab.org.br>. Acesso em: 12 maio 2013.

ANATEL. Material Institucional. Disponível em: <www.anatel.gov.br〉. Acesso em: 13 ago. 2014.

ANDRADE, D. J.; MACEDO, D. G.; DÓRIA, V. E. M. Estudo da distribuição de objetos técnico-informacionais de São José dos Campos no contexto da Região Metropolitana do Vale do Paraíba e Litoral Norte. 2012. 62f. Trabalho de Conclusão de Curso (Graduação em Geografia). Faculdade de Educação e Artes, Universidade do Vale do Paraíba, 2012. 
ATLAS BRASILEIRO DE TELECOMUNICAÇÕES 2013. O mapeamento das redes e dos serviços de telecom no Brasil. São Paulo: Converge Comunicações, 2013.

BECKER, B. K.; EGLER, C. A. G. Brasil: Uma nova potência regional na economiamundo. 4. ed. Rio de Janeiro: Bertrand Brasil, 2003.

BENKO, G. Economia, espaço e globalização: na aurora do século XXI. Trad. Antônio de Pádua Danesi. 2. ed. São Paulo: Hucitec, 1999.

CASTELLS, M. A sociedade em rede. São Paulo: Paz e Terra, 2000.

CESAER. Disponível em: <http://www.ifi.cta.br>. Acesso em: 14 maio 2013.

COSTA, W. M. O processo contemporâneo de industrialização: um estudo sobre a expansão da produção industrial em território paulista. Dissertação (Mestrado em Geografia) - Faculdade de Filosofia, Letras e Ciências Humanas (FFLCH), Universidade de São Paulo, São Paulo, 1982. (datilografado).

DNIT. Material Institucional. Disponível em: <http://www.dnit.gov.br>. Acesso em: 19 ago. 2013.

EMPLASA, Empresa Paulista de Planejamento Metropolitano S.A. Região Metropolitana do Vale do Paraíba e Litoral Norte: Estudo Técnico 2011. Disponível em: <http://www.emplasa.sp.gov.br >.

IBGE, 2010. Material Institucional. Disponível em: <http://www.ibge.gov.br>. Acesso em: 5 jan. 2012.

INFRAERO. Material Institucional. Disponível em: <www.infraero.gov.br>. Acesso em: 13 dez. 2014.

LENCIONI, S. Reestruturação urbano-industrial no Estado de São Paulo: a região da metrópole desconcentrada. In: Território: globalização e fragmentação. São Paulo: Hucitec - Anpur, 1998. p. 199-210.

MEGATELECOM. Material Institucional. $\quad$ Disponível em:<www.megatelecom.com.br>. Acesso em: 7 jun. 2013.

PETROBRAS. Material Institucional. Disponível em: <http://www.petrobras.com.br>. Acesso em: 12 abr. 2013. 
Gasoduto Caraguatatuba - Taubaté. Relatório de Impacto Ambiental -

RIMA. 2006.

Disponível

em:

<http://licenciamento.ibama.gov.br/Dutos/Gasoduto/GASTAU/RIMA_GASODUTO.pd

f>. Acesso em: 12 abr. 2013.

SANTOS, M. Técnica, espaço, tempo: Globalização e meio técnico-científicoinformacional. 2. ed. São Paulo: Hucitec, 1996. 169p.

Natureza do espaço: técnica e tempo, razão e emoção. 4. ed. 7. reimpr. São Paulo: EDUSP, 2012. 377p.

A urbanização brasileira. 5. ed. São Paulo: EDUSP, 2005.

SANTOS, M.; SILVEIRA, M. L. O Brasil: território e sociedade no início do século XXI. 17. ed. Rio de Janeiro: Record, 2013. 475p.

SÃO PAULO. Lei Complementar $n^{\circ} 1.166$, de 9 de janeiro de 2012. Diário Oficial do Estado de São Paulo, São Paulo, 10 jan. 2012. Seção 1, p. 1.

SOUZA, A. A. M. A especialização do lugar: São José dos Campos como Centro da Tecnologia Aeroespacial no País. 2008. 187 f. Tese (Doutorado em Geografia) Faculdade de Filosofia, Ciências Humanas e Letras, Universidade de São Paulo, São Paulo, 2008.

TOLEDO JUNIOR, R. Telecomunicações e uso do território brasileiro. In: SOUZA, M. A. (Org.). Território brasileiro: usos e abusos. Campinas: Edições Territorial, 2003.

Recebimento dos originais: 28/04/2015

Aceitação para publicação: 29/08/2015 